\title{
Study on Measures for Application-oriented Faculty Advancement in Private Universities during Professional Title System Reform
}

\author{
Qi Xiaolin \\ Human Resource Department, \\ Wuhan Technology and Business University, \\ Wuhan, China \\ 10120217@qq.com
}

\author{
Zhan Yuhong * corresponding author \\ College of Management, \\ Wuhan Technology and Business University, \\ Wuhan, China \\ 335255299@qq.com
}

\begin{abstract}
This aim of the study was to analysis the affection of new professional title policy on applied-style faculty advancement in private university, and give some advice for faculty advancement based on the adjustment policy. We reviewed the historical evolution of professional title policies, particularly in the development of "double - qualification" teachers or application-oriented teachers, and reviewed the influence and shortcomings of China's professional title system reforms on faculty advancement. We used 2017 title policy reform in Hubei province as an example, to analyze the main contents of delegating the rights of senior professional title evaluation, and its influence on applied teachers' development of private universities. Finally we suggested the colleges and universities should create some development platforms for applied teachers, to give full play to the title policy guide for teacher development. The new is closely fit the latest national policy, and putting forward some countermeasures for applied teacher development.
\end{abstract}

Keywords-professional title reform; faculty advancement; private university; development platform

\section{INTRODUCTION}

To adapt to and embrace the New Normal of economic development, the Ministry of Education released a statement in 2015 to guide the application-oriented transformation of some common institutions for a college degree. A great number of private universities have engaged in the application-oriented transformation to enhance their graduates' employment rate and quality of employment, and improve their own market competitiveness. In Hubei Province, private universities are developing fast along with the quickly increasing number of teachers, so the faculty advancement has gradually changed from a basic task to a necessity for development including the transformation of teachers. In recent years, Hubei Province has strengthened the reform in the policies on the professional title of teachers in universities,

This paper is funded by the Key Program of the Ministry of in the Twelfth Five-year Plan of the National Office for Education Sciences Planning, that is, Research on the Construction of Performance Evaluation Indicator System for the Classified Management of Application Technology Teachers in Universities (Program No. 2014317), and supported by the Teacher Management Division, Hubei Provincial Dedartment of Education. which exerts a far-reaching effect on private universities.

\section{RESEARCH STATUS}

A. Concept of application-oriented faculty and current status of faculty in private universities

The faculty advancement in private universities mainly relies on the application-oriented training of teachers. At present, it mainly focuses on the training of "doublequalification" teachers. The concept "double-qualification" was put forth by Wang (1991) for the first time. In his opinion, "double-qualification" teachers can satisfy the requirements for capability and quality in five ways, i.e. guiding students in internship, being sent to domestic or overseas plants for training, participating in important teaching and scientific research projects, frequently undertaking technical programs, and partaking in the construction of internship base on campus [1] (Wang, 1991). With regard to training, it was proposed to train the double-qualification teachers by borrowing the experience of private universities in Europe [2] (Wang, 2015). Four measures were put forward for double-qualification faculty advancement [3] (Zhan \& Zhan, 2013). Some scholars elaborated the importance of "double-qualification" teachers to the development of private universities considering private universities' level of running, core competitiveness and talent training quality, and put forth some specific measures for faculty advancement [4] (Li, 2010).

As for the qualification evaluation system for undergraduate education of new universities, the Ministry of Education specifies the following requirements for faculty structure: apart from analyzing the age, academic degree, professional title and other common indicators, it is necessary to evaluate whether the knowledge and capability of faculty satisfy the requirements for training application-oriented teachers based on the positioning of university, especially teachers with professional (industry) qualification and work experience (double-qualification teachers) in the faculty. Also, it gives the detailed standards for recognizing teachers with professional (industry) qualification and work experience. [5] However, faculty advancement is a common problem for every new university based on the statistics of undergraduate qualification evaluation of new universities for years. The 
commonest issue must be the unbalanced faculty structure. Especially, private universities lack the teachers qualified to be trained for application-oriented teachers.

\section{B. Influence of China's professional title system reforms on faculty advancement}

Ever since the People's Republic of China was founded, the professional title system for teachers in universities has experienced several significant reforms. In the academic world, the development stages of China's professional title system for teachers in universities are defined differently, including four stages (Hao and Wang, 1994) [6], six stages (Tian, 2006) [7], five stages (Sun, 2008) [8], and three stages (Niu, 2012) [9]. Regardless of this difference, there is a consensus on the development trend of China's professional title system in the academic world. In other words, professional title was gradually disconnected from post, and determined by administrative leaders or the Party committee within the period from the founding of the People's Republic of China to 1956, through expert review in 1978 and then through appointment of professional technical post after 1986. The rights of professional title evaluation had been gradually delegated by administrative department to universities, and the connection of evaluation with employment was gradually cut off. Professional title was even determined through employment without evaluation. After it was originally connected to salary and other welfares, professional title was disconnected from them and connected again. Moreover, professional title has gradually ended its lifelong assignment. Ye (2009) believed that China's professional title system for teachers in universities experienced the following transitions: transition from identity-based evaluation to contract-based evaluation; transition from focus on academic verification and resource allocation to focus on performance management and incentive \& restraint; transition from centralized control guided by administration to decentralized management guided by academic world; and transition from compulsory system reform to induced system reform. [10]

The development and evolution of professional title policy have played an important role in guiding the growth of teachers in universities. The evaluation criteria were controlled by governmental departments and gradually delegated to employers; so many public universities received the rights of independent professional title evaluation to some extent. Hence, faculty advancement became independent gradually as well, so the study on faculty advancement in universities had moved from the focus on basic capabilities to the focus on the growth-related problems.

\section{Shortcomings of professional title system in application- oriented faculty advancement}

Along with several reforms, professional title system has demonstrated its suitableness, but still faces some problems. After surveying the teachers in the major of engineering in more than 30 universities, Dai and Yang (2003) found that 93\% of application-oriented universities still took the scientific research and academic achievements as the only indicator for evaluating the quality and professional title of teachers, which severely affected the teachers' activeness in improving own practical capabilities [11]. Sun (2008) pointed out that in the existing professional title system, the administrative department still makes most decisions on allocating quota, developing evaluation criteria and evaluating job qualification (except some universities enjoying the rights of evaluation), so employers (universities) can only recommend and employ teachers. As evaluation and employment are not clearly separated, employers have very limited rights of independent employment [12]. Li (2016) collected the rules of 21 universities on the management of professional title evaluation, and found that the publication of papers on periodicals is taken as the rigid indicator in the professional title evaluation of teachers, and universities clearly specify the quantity of papers and the level of periodicals in their documents for professional title management. Due to these provisions, teachers often pursue the quantity of scientific research achievements blindly, and ignore their own duties of teaching [13]. Duan (2015) believed that the existing policies on professional title evaluation are not suitable, and still take papers, books and projects, etc. as the measurement indicators, so most teachers do not pay much attention to the study on practical applications, and have no time to improve own practical operation capability [14]. Zhao and Xiang (2015) argued that professional title evaluation system, as a management system that has the strongest influence on and plays the most important role in faculty advancement of universities, should eliminate the conventional evaluation criteria focusing on scientific research, so as to make teachers grow into the application-oriented faculty actively. The system should change from "the focus on scientific research evaluation" to "the focus on teaching evaluation", and move its attention from "simple academic evaluation" to "application-oriented academic evaluation"[15]. Xie (2016) pointed out that teachers cannot be motivated as the teachers with double qualifications and double capabilities cannot distinguish from common teachers in terms of promotion, appraisement and reward, etc. due to the absence of the corresponding rules on the evaluation management of "double-qualification and double-capability" teachers [16].

In 2017, Hubei delegated the rights of senior professional title evaluation to universities throughout the province (including private universities and independent colleges), so private universities enjoyed the rights to independently evaluate, appoint and issue a certificate to the professor and associate professor. Under such circumstances, some universities became very confident in the future faculty advancement, but some were confused about it. At present, private universities should urgently analyze the influence of this delegation on own development and their teachers, and put forward the measures for application-oriented faculty advancement.

\section{Contents of Delegating The Rights OF SENIOR Professional Title Evaluation in Hubei Province}

In 2017, Human Resources and Social Security Department of Hubei Province issued the Notice of Hubei Professional Title Reform Leading Group on Printing and Distributing the Guiding Opinions on Deepening the Reform of Professional Title System in Universities (YZGZ [2017] No.1), and the Notice of Human Resources and Social Security Department of Hubei Province and Hubei Provincial 
Department of Education on Decentralizing the Rights of Professional Title Evaluation in Universities (YRSF[2017] No. $20)$ to resolve the problems in the professional title evaluation of universities, and carry out the professional title evaluation in the principle that "universities can independently develop evaluation criteria, independently issue a document and certificate for evaluation, and independently use the evaluation results, while relevant government departments will not directly organize the professional title evaluation of teachers in universities, not review the evaluation results, and not issue a document or certificate for this purpose."[17]

\section{A. Allowing universities to independently develop the evaluation criteria based on the provincial evaluation criteria}

Universities are allowed to independently develop the evaluation criteria no lower than the basic requirements of the province based on the evaluation criteria required in the effective document for professional title evaluation in universities, and while considering the needs of own development and the features of discipline, major and post. These evaluation criteria should keep following the guidance of teachers' ethics, give prominence to the features of teaching, attach importance to scientific research capabilities and guide social services.

\section{B. Allowing universities to independently print and issue the document and certificate for professional title}

Universities with independent evaluation are allowed to independently print and issue the document for job qualification and the certificate for qualification based on the results of the evaluation, and affix the seal of their evaluation committee thereon. Hence, when any teacher receiving the qualification in the independent evaluation moves between universities inside the province, the receiving university should organize the experts to evaluate the performance level of the teacher according to job requirements, employ the teacher on this basis and issue its own professional title certificate to the teacher.

\section{Allowing universities to independently use the evaluation results}

To urge universities' independent use of evaluation results, it is allowed that public universities can independently develop the rules on post management, ensure the effective connection between professional and technical title evaluation and employment, and explore the tenure system and the competition for the post. In other words, universities can independently decide how to employ the teachers that have obtained the professional title set the evaluation criteria and manage the talented personnel. However, private universities are not subject to the national restrictions over posts and enjoy the rights to independently use the evaluation results, so they are already promoting the system of "separating evaluation from employment" or "combination of evaluation and employment".

\section{Reforms closely related to double-qualification teachers}

Foreign language is not taken as the prerequisite for professional title evaluation, and there is not a unified requirement for the ability to use a computer. Universities can give opinions based on the job requirements, so the requirements for English and computer skills may be higher for some majors, or lower for others. Actually, this depends on universities' requirements for strategic development, expectations for major and requirements for capability and quality of application-oriented teachers.

The professional technicians that are approved to leave or do part-time work for innovation or starting a business can still apply to their original employers for the professional title according to the rules within 3 years, and their achievements during the period of leave or part-time work can be taken as the basis for professional title evaluation. In other words, universities should not only recognize the years after teachers left universities or when they did part-time work but also set the standards for evaluating their achievements in these years. Actually, this has raised new requirements for universities' design of professional title evaluation criteria.

\section{INFLUENCE OF DELEGATING THE RightS OF EVALUATION ON APPLICATION-ORIENTED FACULTY ADVANCEMENT OF PRIVATE UNIVERSITIES}

Delegating the rights of professional title evaluation to universities shows the resolution of the competent department for education to resolve the problems in the professional title evaluation of universities in a focused manner. As professional title policy can guide the growth of teachers for a long time, its dramatic change will lead to the reflection of teachers in universities and their management departments. At present, teachers in private universities are often concerned about the difficulty in moving due to the decreasing value of certificate issued by universities, the increasing difficulty in promotion as universities increase the standards for evaluation, the restricted number of posts in universities due to cost control, and the interference with the fairness of evaluation due to the administrative powers or human factors of universities. How can these problems be addressed?

\section{A. Independent evaluation guides universities to adjust their evaluation criteria based on the needs of development}

Universities should adjust their evaluation criteria in consideration of own needs in strategic development, and not simply remove or add some rules. The new professional title policy allows universities to independently develop the evaluation criteria no lower than the basic requirements in the effective document for professional title evaluation in universities while considering the needs of own development and the features of discipline, major and post. This responsibility is mainly assumed by the leaders of university or college and the departments in charge of policy formulation and execution. As evaluation criteria belong to guiding policies affecting the overall development of universities, the departments of universities are required to create conditions and construct platforms for realizing the evaluation criteria for teachers.

The delegation of evaluation rights also challenges the foresight of university and college leaders for strategic development. Leaders must, from the perspective of strategic development, judge which discipline should be particularly developed and what talented teachers are needed in these 
disciplines. If there is not the strategic guidance of the whole university, colleges and disciplines will lose their focus on development, and it will be difficult to develop the professional title policy in a focused manner. For this reason, it is a primary task for every application-oriented university to establish an evaluation system suitable for the development of application-oriented faculty.

\section{B. Independent issuance of professional title certificate will guide the reasonable mobility of talented teachers}

Talented teachers should not be recruited on the basis of their certificates, but in consideration of the university's actual needs in discipline and major construction. As stipulated in the new professional title policy, "when any teacher receiving the qualification in the independent evaluation moves between universities inside the province, the receiving university should organize the experts to evaluate the performance level of the teacher according to job requirements, employ the teacher on this basis and issue its own professional title certificate to the teacher." Hence, a teacher should comply with the requirements of the receiving university for the performance and capability of the same professional level, which can help private universities rationally attract talented teachers to some extent, and realize more rational mobility of teachers.

\section{Private universities will not impose a quota on the} promotion to senior professional title within a short period

In private universities, a lower percentage of full-time teachers have the senior professional title. As revealed in the survey 2016, only $17.4 \%$ of full-time teachers in private universities possessed sub-senior professional title (only $2.5 \%$ had the senior professional title). It is much lower than the evaluation requirement, that is, over $30 \%$, so private universities depend much on part-time teachers with the senior professional title. However, private universities must, in the long run, have their own plan for talent building, including fixed posts and arrangements for talented teachers. This requirement does not relate to the delegation of evaluation rights but relates to universities' needs of own development.

\section{Delegating the rights of evaluation will inevitably increase the power of supervision}

Universities should establish the strict internal supervisory mechanism. To middle-level managers of universities, the delegation of evaluation rights will challenge their level of policy development, the capability of execution and management skills. According to the new professional title policy, "universities shall establish internal supervisory system..., and investigate the responsibilities of the responsible personnel according to the relevant rules if any major violation of rules is found". The administrative departments of universities should not directly interfere with the review of the evaluation committee, while the evaluation experts, evaluation procedure, rules and announcement for public review must be all supervised. Meanwhile, the Professional Title Reform Office of Hubei Province works with the educational department to reinforce the macroscopic management, public service, in-process and post-supervision of professional title evaluation in universities. Applicants and teachers passing the evaluation are checked randomly, and the evaluation process is patrol checked. If any problem is found, it will be handled in a timely manner, and any personnel involved in such problem will be investigated according to the relevant rules.

\section{COUNTERMEASURES}

Under the current background of delegating the rights of senior professional title evaluation, and professional title system reform, private universities in Hubei Province should create the professional title evaluation conditions suitable for application-oriented faculty advancement as soon as possible on one hand, and establish the platform for the evaluation of application-oriented faculty in an all-around way, so as to facilitate the improvement of teachers' application-oriented skills and fulfill the objective of application-oriented talent training. Now we should give several countermeasures for application-oriented faculty advancement based on professional title system reform.

\section{A. Developing the senior professional title evaluation criteria suitable for application-oriented faculty advancement}

From the perspective of development, delegating the rights of senior professional title evaluation to universities must bring more benefits than troubles to the development of private universities. The key of development must be whether universities can grasp this opportunity to establish the guiding evaluation indicators in match with their development strategy. Universities should keep the purpose of application-oriented faculty advancement in the design of indicators guiding application-oriented faculty advancement, and fully demonstrate and increase the application-oriented contents in the rules on professional work capability, performance and achievements. Universities should change the current status of "attaching importance to scientific research, overlooking teaching and practice", increase the requirements for teaching and practice and improve the internal drive to the applicationoriented training of teachers. Additionally, universities should eliminate the exclusive reliance on the comments from authoritative, core or common periodicals in the evaluation of papers, but pay more attention to the role of teaching and scientific research papers in improving teaching quality, talent training and social service. The single channel of further education for teachers should be changed, while teachers are encouraged to do practical work in enterprises and provide services with own professional skills. Moreover, universities should simply the procedure for recognizing and evaluating teachers from enterprises, and urge senior management personnel with rich experience in enterprises to join them.

\section{B. Establishing the platform for in-depth cooperation \\ between universities and enterprises to create the conditions for teachers to further understand enterprises}

For the internship and employment of students, private universities have constructed a large number of internship and employment bases. Universities can further deepen the cooperation with the existing bases by encouraging teachers to do practical work in enterprises and participate in the production and service of enterprises. On the other hand, teachers, who get familiar with the operation of enterprises, will be able to provide the knowledge-based services for 
enterprises, including training, consulting and scheme preparation, etc. Only when teachers are familiar with the operation of enterprises, they can provide the improvement scheme to be adopted, and will confidently convert the practical experience in enterprises into teaching contents. In this case, universities should create the opportunities for teachers to get experience in the society and enterprises, and encourage teachers to participate in all kinds of social activities, so as to generate social benefits. Moreover, teachers are also encouraged to leave or do part-time work for innovation and starting a business, so as to make achievements helpful to their teaching work.

\section{Creating the all-directional classroom evaluation platform to give play to the role of teachers' self-evaluation}

At present, most teaching quality evaluations mainly rely on students with the assistance of supervisory and administrative departments, so the evaluated teachers do not take a part in these evaluations, but accept the evaluation results passively. Teachers' self-evaluation shows their allaround reflection on own teaching contents, process, and results. The comprehensive classroom teaching evaluation can help teachers understand all aspects of classroom teaching objectively, help identify the gap of self-evaluation from evaluation by students and fellow evaluation, and help teachers improve own teaching level. Hence, universities should establish the all-directional classroom evaluation platform and increase the percentage of teachers' selfevaluation to make teachers play a more active part in teaching evaluation and give play to the role of teachers' selfevaluation.

\section{Developing the academic platform for teaching innovation to encourage teams to demonstrate the innovative achievements of application-oriented teaching}

Universities should develop the teaching innovation platform for teachers to communicate about teaching methods and techniques. For instance, universities should hold the annual meeting for academic communication about teaching innovation, and encourage teachers to give a $15 \mathrm{~min}$ speech on behalf of the team or themselves with regard to their teaching reform and innovation for a course in the past school year, and then have a $15 \mathrm{~min}$ communication and exchange. In terms of topics, the contents of teaching reform for several topics can be demonstrated at different places simultaneously. In the oneday academic event of annual teaching innovation, 6-8 teams can demonstrate for 4 topics apart from keynote speech. A meeting of communication allows around 30 teams of teachers to demonstrate their achievements. Teachers may choose to be present at any speech based on own interests, or apply for delivering a speech based on the topics. It is believed that all attending teachers must have great harvests no matter whether they give or attend a speech.

\section{E. Jointly creating the inter-university teaching competition platform to encourage teachers to polish their teaching level}

Teaching competition is a very effective way to polish the teaching level, but there are very few opportunities for private universities to participate in the provincial teaching competitions. If teachers participate only in university-level teaching competitions, it is very difficult for them to embrace a wide view. Teachers need the opportunities to participate in teaching competitions, learn about the teaching level of teachers in similar universities and receive the guidance from senior teachers. Hence, private universities may independently establish the inter-university teaching competition platform, organize the inter-university teaching competitions, and create the environment for teachers to improve their teaching, so as to create the opportunities for improving their teaching level. Moreover, private universities can create the opportunities for teachers to communicate and learn from one another across majors.

\section{F. Developing the teacher workshop platform to encourage teachers to open the application-oriented courses for} teachers and students

Universities should create a teacher workshop platform for teachers, that is, a communication and learning platform. On this platform, teachers can design the course they are proficient in teaching into one workshop or a series of workshops. In each workshop, teachers can spend 2 hours in explaining a topic thoroughly. Every teacher is allowed to apply for the leading role in the speeches of the workshop. Similarly, every teacher may choose to participate in the workshop, and evaluate its effect. The topic and content of these workshops may be changed every year as selected and may be modified and improved on the basis of participants' evaluation opinions. These workshops must be highly application-oriented to attract many interested audiences, and teachers often have higher requirements than students. Hence, leading teachers must meet higher requirements in the design of application-oriented courses. In the process of communication, teachers can provide more unbiased opinions and make more contributions to the improvement of teaching level.

\section{CONCLUSION}

Delegating the rights of professional title evaluation to universities shows the competent department for education tried to give full autonomous of running schools to the university's, which was a double-edged sword for the development of teachers in private Universities. The administrators of universities can formulate the professional title policies meet the development of the universities, which is good news. At the same time, it is considered bad news for teachers individual in the short term because the turnover will become difficult for the title identification problem. The succeed of application-oriented faculty advancement in private universities, depends on the effectively taken advantages of the title reform policy, and build some working platform conducive to the development of faculty.

\section{REFERENCES}

[1] Wang Yicheng. On how to train “double-qualification” teachers [J]. Researches in Higher Education of Engineering, 1991 (2): 49-50, 53.

[2] Wang Wenting. Research on Double-qualified Teaching Staff's Construction Based on the University of Applied Technology in China [D]. Harbin: Harbin University of Science and Technology. 2005. 
[3] Zhan Xuewen \& Zhan Qiuwen. Study on faculty advancement of local application-oriented universities [J]. Journal of Huangshan University, 2013 (4): 102-104.

[4] Li Xiaoxia. Faculty advancement of application-oriented universities from the perspective of talent training $[\mathrm{J}]$. Chinese Geological Education, 2010 (4): 59-62.

[5] Understanding the Qualification Assessment Indicator System for Undergraduate Teaching. 2015.

[6] Hao Zhenwen \& Wang Meifang. The history and future of professional titles for teachers in China's universities [J]. Journal of Shandong Normal University(Social Science Edition), 1994 (sd):67-70.

[7] Tian Zijun. The historical evolution of the appraisement and engagement system of the professional title of China's college and university teachers $[\mathrm{J}]$. Journal of Hunan University of Science and Engineering, 2006, 27 (3): 265-268.

[8] Sun Fubing. Research on the Professional Title System for Teachers in Universities [D]. Shandong Normal University, 2008.

[9] Niu Fengrui. Structure and historical changes of the faculty professionaltitle system in China-The analysis from the perspective of historical institutionalism [J]. China Higher Education Research, 2012 (10): 71-75.

[10] Ye Fenmei. Reflection on the evolutionary logic and system of professional titles for teachers in universities at the 60th anniversary of the People's Republic of China [J]. Modern University Education, 2009 (6): 33-38.
[11] Sun Fubing. Research on the Professional Title System for Teachers in Universities [D]. Shandong Normal University, 2008.

[12] Li Zheyi. Research on the System of Teachers' Professional Title Evaluation-A Case Study of the Teachers' Title Evaluation Methods in 21 Universities [D]. Henan University, 2016.

[13] Dai Wenshuang \& Yang Jianping. The effective way to improve the practical capabilities of faculty in application-oriented universities [J]. Journal of Liaoning Institute of Science and Technology, 2013 (4): 5557.

[14] Duan Zhenfeng. On the training of “double-qualification” teachers in local application-oriented universities [J]. Education and Vocation, 2015 (13): 68-70.

[15] Zhao Xiangyu \& Xiang Chaochun. Study on the application-oriented faculty advancement of local universities [J]. Education and Vocation, 2015 (19): 57-59.

[16] Xie Jun. Analysis on the "double-qualification and double capability" faculty advancement under the background of transformational development of local universities [J]. Contemporary Education Research and Teaching Practice (Electronic Edition), 2016 (9): 125-126.

[17] Notice of Human Resources and Social Security Department of Hubei Province and Hubei Provincial Department of Education on Decentralizing the Rights of Professional Title Evaluation in Universities (YRSF[2017] No. 20), Notice of Hubei Professional Title Reform Leading Group on Printing and Distributing the Guiding Opinions on Deepening the Reform of Professional Title System in Universities (YZGZ [2017] No.1). 